\title{
Projection of subtropical gyre circulation and associated sea level changes in the Pacific based on CMIP3 climate models
}

\author{
Xuebin Zhang $\cdot$ John A. Church $\cdot$ Skye M. Platten • \\ Didier Monselesan
}

Received: 22 February 2013/Accepted: 30 July 2013/Published online: 18 August 2013

(C) The Author(s) 2013. This article is published with open access at Springerlink.com

\begin{abstract}
For all of the IPCC Special Report on Emission Scenarios (SRESs), sea level is projected to rise globally. However, sea level changes are not expected to be geographically uniform, with many regions departing significantly from the global average. Some of regional distributions of sea level changes can be explained by projected changes of ocean density and dynamics. In this study, with 11 available Coupled Model Intercomparison Project Phase 3 climate models under the SRES A1B, we identify an asymmetric feature (not recognised in previous studies) of projected subtropical gyre circulation changes and associated sea level changes between the North and South Pacific, through analysing projected changes of ocean dynamic height (with reference to 2,000 db), depth integrated steric height, Sverdrup stream function, surface wind stress and its curl. Poleward expansion of the subtropical gyres is projected in the upper ocean for both North and South Pacific. Contrastingly, the subtropical gyre circulation is projected to spin down by about $20 \%$ in the subsurface North Pacific from the main thermocline around $400 \mathrm{~m}$ to at least 2,000 m, while the South Pacific subtropical gyre is projected to strengthen by about $25 \%$ and expand poleward in the subsurface to at least $2,000 \mathrm{~m}$. This asymmetrical distribution of the projected subtropical gyre circulation changes is directly related to differences in projected changes of temperature and salinity between the
\end{abstract}

Electronic supplementary material The online version of this article (doi:10.1007/s00382-013-1902-x) contains supplementary material, which is available to authorized users.

X. Zhang $(\bowtie) \cdot$ J. A. Church · S. M. Platten · D. Monselesan Centre for Australian Weather and Climate Research and Wealth from Oceans Flagship, CSIRO Marine and Atmospheric Research, GPO Box 1538, Hobart, TAS 7001, Australia e-mail: xuebin.zhang@csiro.au
North and South Pacific, forced by surface heat and freshwater fluxes, and surface wind stress changes.

Keywords Sea level change $\cdot$ CMIP3 $\cdot$ Subtropical gyre circulation $\cdot$ Poleward expansion

\section{Introduction}

Global sea level rise and its impacts on coastal regions is one of the most critical research subjects related to global climate change. According to the Intergovernmental Panel on Climate Change (IPCC) Fourth Assessment Report (AR4), the global-mean sea level, not including the potential dynamic response of ice sheets, is projected to rise by $18-59 \mathrm{~cm}$ by $2090-2099$ relative to $1980-1999$ (Meehl et al. 2007). However, sea level changes are not expected to be geographically uniform (e.g., Meehl et al. 2007; Landerer et al. 2007; Yin et al. 2010; Church et al. 2010). For the Coupled Model Intercomparison Project Phase 3 (CMIP3), global Atmosphere-Ocean General Circulation Models (AOGCMs) provide valuable information on the dynamical ocean component of future sea level change (e.g., Lowe and Gregory 2006), which needs to be added to the regional sea level contributions from glaciers and ice caps, and ice sheets in Greenland and Antarctica, and also corrected for glacial isostatic adjustment (e.g., Davis and Mitrovica 1996).

The dynamic sea level (DSL), i.e., regional sea level relative to the global mean, which is determined by the dynamical balance associated with ocean density distribution and circulation, can be significant in climate models (Fig. 10.32 of Meehl et al. 2007; Yin et al. 2010). For example, the spatial standard deviation (relative to the global average) of multi-model mean of sea level change 
by 2080-2099 relative to 1980-1999 as shown in IPCC AR4 is on the order of $0.08 \mathrm{~m}$ (Meehl et al. 2007). Regional distributions of DSL changes can be mostly explained by regional steric sea level changes which can be derived from local temperature and salinity change (e.g., Lowe and Gregory 2006; Meehl et al. 2007; Landerer et al. 2007; Church et al. 2010). However, Significant intermodel differences exist in projections of regional DSL change (refer to Fig. 10.32 of Meehl et al. 2007). The reason for these inter-model differences is inadequately understood.

Though often regarded as an ocean surface parameter, sea level integrates ocean variability from the surface to the ocean floor and is thus determined by ocean interior changes. In addition, subsurface water density changes can provide information on changes of ocean circulation and related steric sea level (or similarly dynamic height) through the water column, which can help to diagnose and understand surface sea level change. In this study, we report an asymmetry of subtropical gyre circulation changes and associated sea level changes between the North Pacific (NPac) and South Pacific (SPac), and attempt to understand the underlying mechanisms responsible for such an asymmetric distribution.

In Sect. 2, we introduce the CMIP3 models and related data processing and methodology. The asymmetrical distribution of subtropical gyre circulation changes and related sea level changes are discussed in Sect. 3. Possible underlying mechanisms are given in Sect. 4 with a final discussion and conclusions presented in Sect. 5 .

\section{CMIP3 models, data processing and methodology}

The CMIP3 climate model simulations used by the IPCC AR4 are archived by the Program for Climate Model Diagnosis and Intercomparison (PCMDI, website: http:// wwww-pcmdi.llnl.gov/). To project future climate change associated with increasing concentrations of greenhouse gases (GHGs), CMIP3 AOGCMs were integrated under different emission scenarios (Nakicenovic and Swart 2000). In our current study, we focus on the Special Report on Emission Scenario (SRES) A1B which has a wider range of model availability than the other scenarios and usually produces projections in the middle of range of the full suite of scenarios (refer to Table 10.7 of Meehl et al. 2007 for the global sea level rise projections under six emission scenarios).

There are three standard CMIP3 experiments: (I), a twentieth-century historical simulation $(20 \mathrm{c} 3 \mathrm{~m})$ from about 1850 to 2000 which is designed to reproduce historical climate states; (II), future climate projection simulations (SRES) under various emissions scenarios from 2001 to
2100 (or further) which are designed to simulate future climate change; (III), a pre-industrial control simulation (CTRL) under constant pre-industrial forcing for several hundred years, which can be used to estimate natural climate variability in the model simulation and also to identify and correct for model drift. Ideally CTRL experiments should not display any long-term trends, nonetheless many models still do. These spurious long-term trends are often referred to as "model drift" (Sen Gupta et al. 2012). These trends are associated with the long time scales for the ocean to come into equilibrium with the atmosphere. In some cases, coupling shock, initialization or model numerics can also play roles. Sen Gupta et al. (2012) examined the drift in CMIP3 models in detail and found the oceanic variables (especially below depths of 1,000-2,000 m) usually have a larger drift than atmospheric variables. Therefore, we dedrift using the following formula,

$\overline{x^{\prime}(t)}=\left[\overline{x_{\text {SRES }}(t)}-\overline{x_{\text {SRES }}\left(t_{0}\right)}\right]-\left[\overline{x_{C T R L}(t)}-\overline{x_{C T R L}\left(t_{0}\right)}\right]$

where $\mathrm{x}$ is the climate variable of interest, $\mathrm{x}^{\prime}$ the dedrifted climate variable, $t_{0}$ base period from 1981 to 2000 . Overbars represent 20-year averaging, which suppress possible impacts from interannual to decadal variability. The same dedrifting formula has also been used by Pardaens et al. (2011) in their regional sea level projection study. By applying the above dedrifting procedure, any artificial changes (relative to the base period) in the control runs are removed from corresponding SRES runs. Some CMIP3 models are not included in our study because of the unavailability of the corresponding control runs.

Table 1 lists all 11 CMIP3 models used in this analysis. Detailed information about these models can be found in Randall et al. (2007). For consistency, we use all 11 models to calculate multi-model averages of each physical parameter. For that purpose, each model is regridded to a common grid before the multi-model averages are calculated. The common grid has a uniform $1^{\circ} \times 1^{\circ}$ resolution horizontally, and has 50 vertical levels which are identical to the setup in the GFDL-CM2.1 model (Delworth et al. 2006).

Natural variability, in particular the decadal-to-interdecadal variability, can be mixed with climate change signals, and it's not an easy task to clearly separate the two signals. The 20-year averaging (Eq. 1) does tend to suppress influences of natural variability on decadal and shorter time scales within each individual model. Moreover, ensemble averaging of multiple models can also significantly reduce the impacts of decadal to interdecadal variability, since each model tends to have different phases of the natural variability. So the above processing steps, i.e., 20-year averaging of individual model then followed by multi-model averaging, should help identify the signals associated with future climate change under various 
Table 1 CMIP3 models used in this study. More details about models and related references can be found in the Chapter 8 of the IPCC AR4 (Randall et al. 2007)

\begin{tabular}{llll}
\hline Model name & Oceanic model & Oceanic Resolution & Country \\
\hline BCCR-BCM2.0 & MICOM2.8 & $0.5-1.5^{\circ} \times 1.5^{\circ}, \mathrm{L} 35$ & Norway \\
CGCM3.1(T63) & MOM1.1 & $0.9^{\circ} \times 1.4^{\circ}, \mathrm{L} 29$ & Canada \\
CNRM-CM3 & OPA8.1 & $0.5-2^{\circ} \times 2^{\circ}, \mathrm{L} 31$ & France \\
CSIRO-MK3.5 & MOM2.2 & $0.8^{\circ} \times 1.9^{\circ}, \mathrm{L} 29$ & Australia \\
ECHO-G & HOPE-G & $0.5-2.8^{\circ} \times 2.8^{\circ}, \mathrm{L} 20$ & Germany/Korea \\
FGOALS-g1.0 & LICOM1.0 & $1.0^{\circ} \times 1.0^{\circ}, \mathrm{L} 16$ & China \\
GFDL-CM2.0 & OM3P4 & $0.3-1.0^{\circ} \times 1^{\circ}, \mathrm{L} 50$ & USA \\
GFDL-CM2.1 & OM3.1P4 & $0.3-1.0^{\circ} \times 1^{\circ}, \mathrm{L} 50$ & USA \\
MIROC3.2 (medres) & COCO3.3 & $0.5-1.4^{\circ} \times 1.4^{\circ}, \mathrm{L} 43$ & Japan \\
MRI-CGCM2.3.2 & Bryan-Cox & $0.5-2.0^{\circ} \times 2.5^{\circ}, \mathrm{L} 23$ & Japan \\
UKMO-HADCM3 & Cox & $1.25^{\circ} \times 1.25^{\circ}, \mathrm{L} 20$ & UK \\
Ensemble numbers & 11 & & \\
\hline
\end{tabular}

emission scenarios. As a simple verification, the spatial patterns of sea level change projection (Fig. 1d) identified by the above processing steps are very different from those of sea level variability on decadal-to-interdecadal time scales which are closely related to the Pacific Decadal Oscillation as identified by Zhang and Church (2012) (refer to their Figs. 4 and S2).

The DSL, defined as regional sea level deviation from the global mean, is derived from "ZOS" output from CMIP3 models with global mean removed (e.g., Yin et al. 2010).

In the following, we introduce two parameters which are critical for our current analysis and are not directly available from CMIP3 model outputs.

\subsection{Dynamic height (DH)}

DH is a commonly used parameter which can be derived straightforwardly from hydrographic profiles (e.g., Gill 1980),

$$
\Delta D(p 1, p 2)=\int_{p 1}^{p 2} \delta(S, T, p) d p
$$

where $\mathrm{p} 1$ and $\mathrm{p} 2$ are two reference pressure levels (p2 is set as 2,000 db in the current study), $\mathrm{S}$ salinity, $\mathrm{T}$ temperate, $\mathrm{p}$ pressure, and $\delta$ the specific volume anomaly $\delta(S, T, p)=1 /$ $\rho(S, T, p)-1 / \rho\left(35 \mathrm{psu}, 0{ }^{\circ} \mathrm{C}, \mathrm{p}\right)$ (unit: $\left.\mathrm{m}^{3} \mathrm{~kg}^{-1}\right)$, where $\rho$ is the density which depends on $\mathrm{S}, \mathrm{T}$ and $\mathrm{p}$. DH measures geopotential and has units of dynamic meters (1 dyn $\mathrm{m}=10 \mathrm{~m}^{2} \mathrm{~s}^{-2}$ ). One dynamic meter corresponds closely to one geometric meter of sea level height, therefore it is a very convenient parameter to study dynamic topography at various depths. DH at the sea surface, referenced to some deep layer of "no-motion" where horizontal pressure gradients are assumed to be small, is commonly used as a good substitute for sea surface height due to their close resemblance (e.g., Gilson et al. 1998; Roemmich et al. 2007), but they are not identical because not all processes are considered in the DH calculation (e.g., contribution from deep ocean below the reference layer or motion at the reference level).

In the current study, DH is computed from annual temperature and salinity profiles from CMIP3 models by vertically integrating the specific volume anomaly referenced to $2,000 \mathrm{db}$. To focus on the regional distribution, the global mean has been removed from the sea level field. Similarly, depth-dependent global means have also been removed from both $\delta$ and DH fields. In the following, we will call this regional DH relative to global mean Regional DH (RDH).

To separate the contribution of temperature and salinity to both $\delta$ and $\mathrm{DH}$, we also calculate the thermosteric $\mathrm{DH}$ $\left(\Delta D_{T}\right)$ and halosteric $\mathrm{DH}\left(\Delta D_{H}\right)$,

$$
\begin{aligned}
\Delta D_{T}(p 1, p 2) & =\int_{p 1}^{p 2} \delta_{T}(35, T, p) d p \\
& =\int_{p 1}^{p 2}[1 / \rho(35, T, p)-1 / \rho(35,0, p)] d p \\
\Delta D_{H}(p 1, p 2) & =\int_{p 1}^{p 2} \delta_{H}(S, 0, p) d p \\
& =\int_{p 1}^{p 2}[1 / \rho(S, 0, p)-1 / \rho(35,0, p)] d p
\end{aligned}
$$

where $\delta_{T}\left(\delta_{H}\right)$ is the thermosteric (halosteric) contribution to the specific volume anomaly $\delta$. The above decomposition of $\Delta D$ into $\Delta D_{T}$ and $\Delta D_{H}$ is approximate since density is a nonlinear function of temperature, salinity and pressure, but $\Delta D$ is very close to the sum of $\Delta D_{T}$ and $\Delta D_{H}$ (refer to Fig. 2 which shows the difference $\Delta D-$ $\left.\left(\Delta D_{T}+\Delta D_{H}\right)\right)$. 
Fig. 1 The multi-model average of dynamic height (in dynamic centimetres with reference to $2,000 \mathrm{db}$ ) at a $0 \mathrm{~m}$, b $100 \mathrm{~m}$ and c $600 \mathrm{~m}$ depth, its mean distribution from $20 \mathrm{c} 3 \mathrm{~m}$ runs over 1980-1999 (shading) and its change under the SRES A1B scenario (SRESA1B$20 \mathrm{c} 3 \mathrm{~m}$, shown as contours) over 2080-2099 relative to

1980-1999. d Same as (a), but for dynamic sea level (in cm). e, f Same as $(\mathbf{b}, \mathbf{c})$, but for the zonal average over $180-160^{\circ} \mathrm{W}$. The SRESA1B-20c3m changes are doubled in panels $\mathbf{e}$ and $\mathbf{f}$ for better display (a) 0 Meter

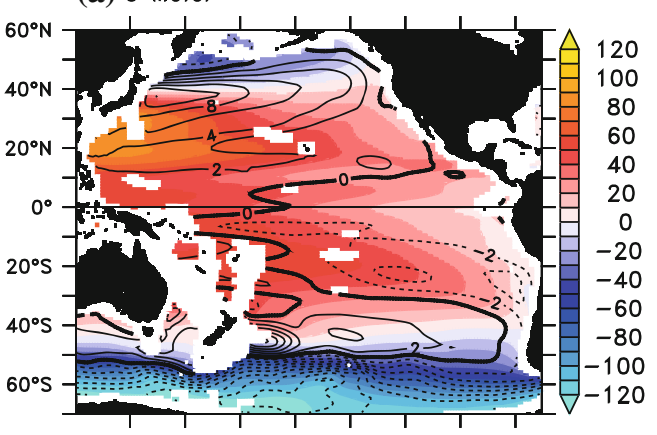

(b) 100 Meter

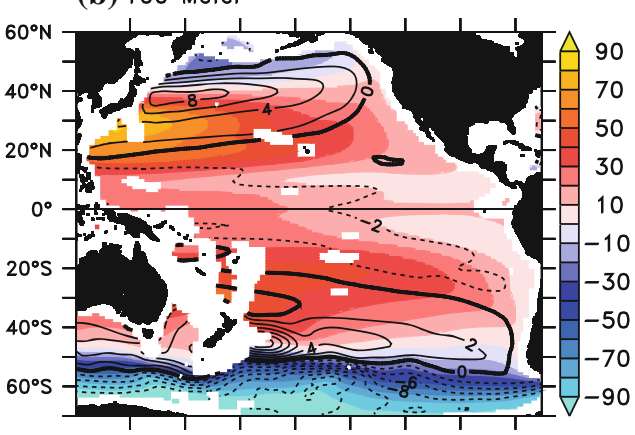

(c) 600 Meter

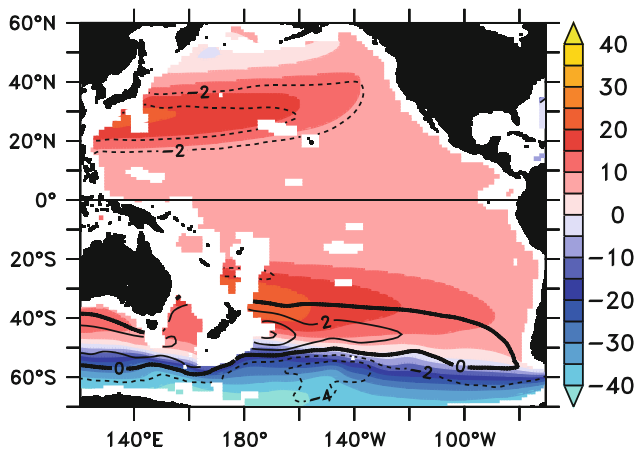

(d) sea level

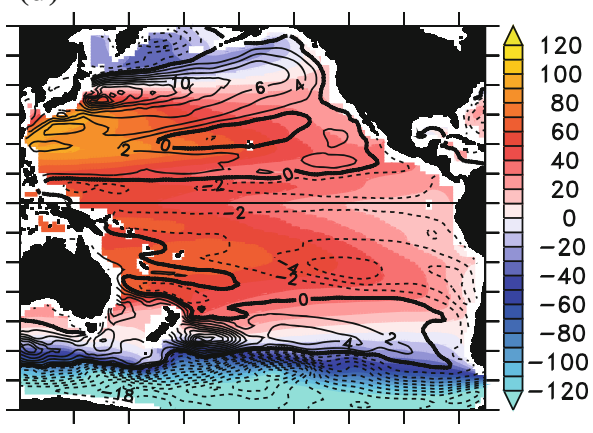

(e) 100 Meter, $180-160^{\circ} \mathrm{W}$

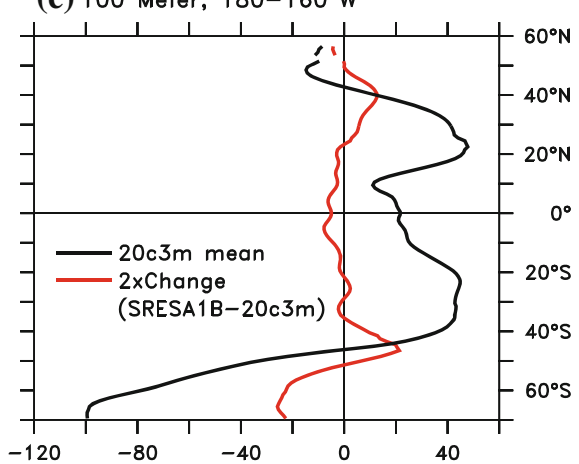

(f) 600 Meter, $180-160^{\circ} \mathrm{W}$

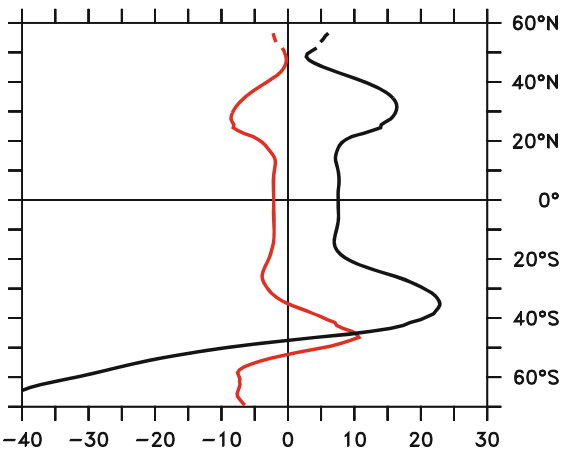

Note the differences between $\mathrm{DH}$ and steric height $(\mathrm{SH})$. While DH is popularly used in dynamic oceanography and meteorology, $\mathrm{SH}$ is a term commonly used in the sea level research community. Sea level can be generally decomposed into two components: steric component and mass component. The steric component is associated with sea water density change, which is defined as the vertical integral of relative density change $(-d \rho / \rho)$ over some depth range (e.g., 0-700 m), i.e.,

$\eta_{S H}=-\int_{Z 1}^{Z 2} \frac{d \rho}{\rho} d z$

where $\mathrm{Z} 1$ and $\mathrm{Z} 2$ are two depth levels and Z2 is often set as $0 \mathrm{~m}, d \rho$ is the local density change (positive for density increase) and $\rho$ is the local density. By its definition and underlying assumption, DH is defined relative to the "nomotion" reference layer and thus cannot be calculated over the regions shallower than the reference layer (e.g., 2,000 db in current study), while $\mathrm{SH}$ calculation usually isn't constrained by water depth. Another important difference is that in DH calculation (Eq. 2) specific volume anomaly is defined relative to specific volume at the same pressure with temperature of $0{ }^{\circ} \mathrm{C}$ and salinity of $35 \mathrm{psu}$ (Gill 1980), while the density change in SH calculation is usually defined relative to local density (e.g., Landerer et al. 2007; Yin et al. 2010). By using the same reference specific volume in $\mathrm{DH}$ calculation, a three-dimensional distribution of $\mathrm{DH}$ above the reference layer can be derived from available temperature and salinity fields. In this study, we are interested in deriving both mean and change fields of DH from corresponding mean and change fields of 
(a) Steric

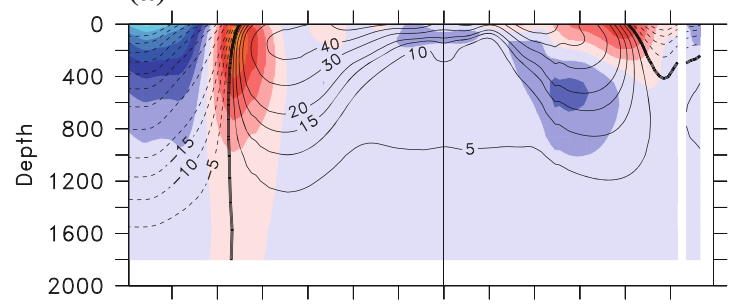

(b) Thermosteric

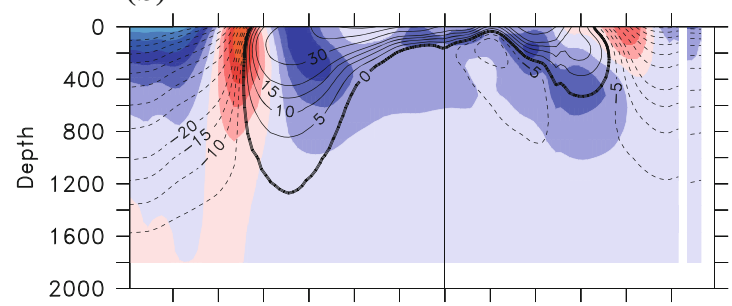

(c) Halosteric

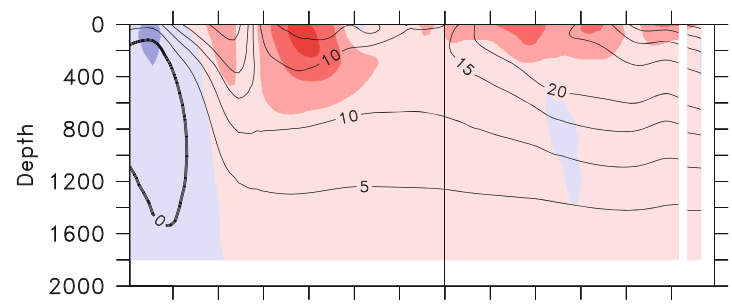

(d) Steric-(Thermosteric+Halosteric)

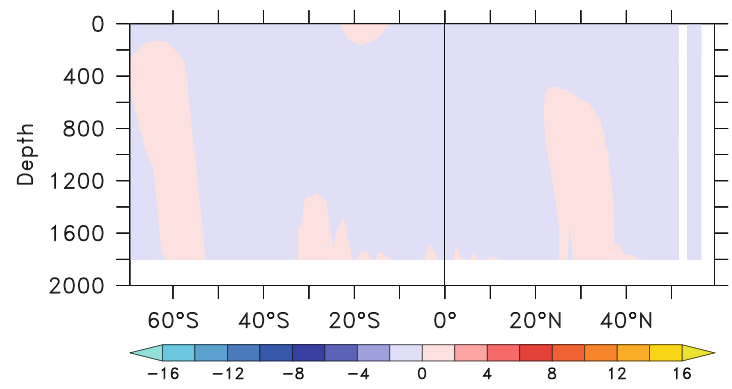

Fig. 2 a The multi-model average of dynamic height change (in dynamic centimetres with reference to 2,000 db) under the SRES A1B scenario (SRESA1B-20c3m, shading) over 2080-2099 relative to $1980-1999$ averaged over $180-160^{\circ} \mathrm{W}$, and its b thermosteric component and $\mathbf{c}$ halosteric components. Mean distributions from 20c3m runs over 1980-1999 are also shown by contours in panels (ac). d Difference between a dynamic height and the sum of its

temperature and salinity. In contrast, by definition $\mathrm{SH}$ is usually calculated based on local density change, thus only the change field is meaningful and can be derived for $\mathrm{SH}$. Despite of above differences, projected changes of $\mathrm{DH}$ under future climate change follow projected $\mathrm{SH}$ changes well when the pressure range in $\mathrm{DH}$ calculation matches the depth range in $\mathrm{SH}$ calculation, that is, p1-p2 (e.g., $0-2,000 \mathrm{db})$ in Eq. 2 corresponds to Z2-Z1 (0 to $-2,000 \mathrm{~m}$ ) in Eq. 5 (By assuming hydrostatic equilibrium,
Specific Volume Anomaly Change $\left(10^{-4} \mathrm{~m}^{3} / \mathrm{kg}\right)$

(e) Steric

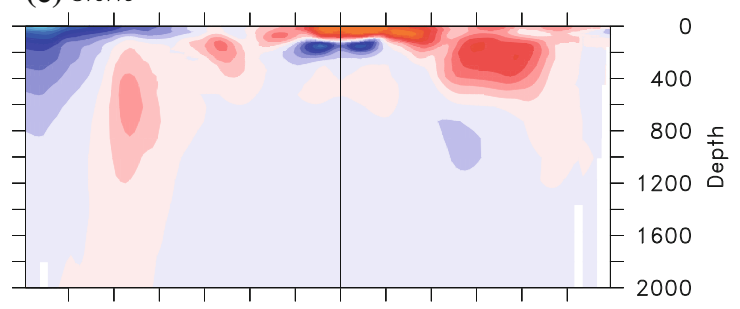

(f) Thermosteric

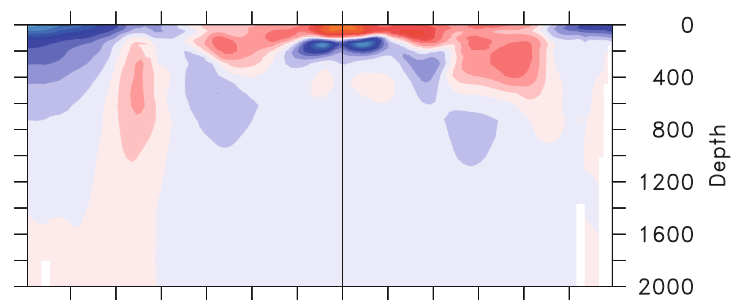

(g) Halosteric

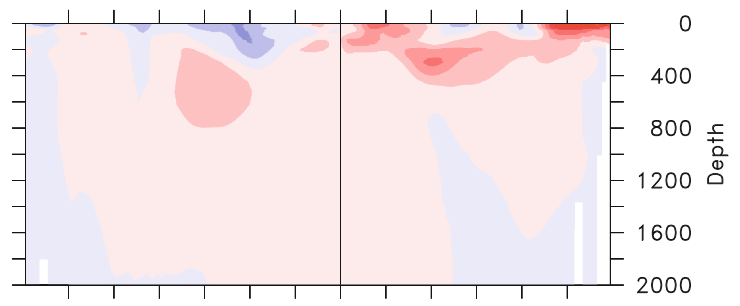

(h) Steric-(Thermosteric+Halosteric)

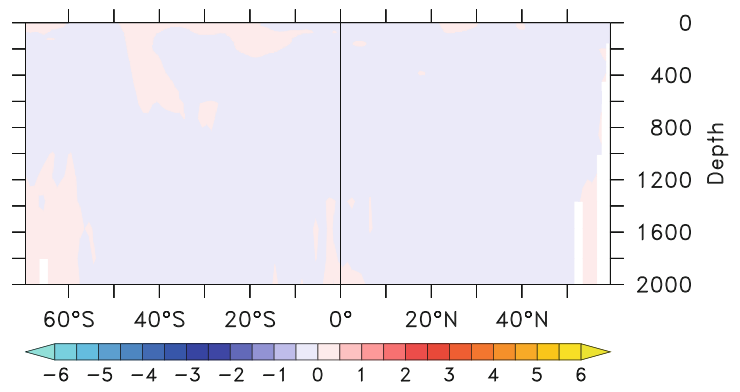

b thermosteric and c halosteric components (refer to Eqs. 2-4). The depth-dependent global means are removed from each panel, thus positive (negative) values indicate higher (lower) local dynamic height change than the global average. $\mathbf{e}-\mathbf{h}$ Same as (a-d), but for specific volume anomaly change (in $10^{-4} \mathrm{~m}^{3} \mathrm{~kg}^{-1}$ ). Vertical distribution of dynamic height change as shown in panel a from each model is shown in the supplementary Fig. S1

the integration over pressure in Eq. 2 can be converted to an depth integration, thus can be compared to the depth integration in Eq. 5).

\subsection{Sverdrup stream function (SSF)}

The Sverdrup Balance (1947) relates steady-state largescale ocean circulation to surface wind-stress curl forcing and can explain much of the large-scale circulation in the 
Pacific (e.g., Hautala et al. 1994; Deser et al. 1999). The SSF can be derived by zonal integral of wind stress curl westward from the eastern boundary along each latitude.

$\psi(x)=-\int_{x}^{x_{E}} \frac{\nabla \times \tau}{\rho_{0} \beta} d x+\psi\left(x_{E}\right)$

where $\psi$ is the SSF, $\rho_{0}$ the reference sea-water density, $\beta$ the Beta parameter $(\beta=\partial f / \partial y)$ representing the change of the Coriolis parameter with meridional distance, $\nabla \times \tau$ surface wind-stress curl, and $\psi\left(x_{E}\right)$ the SSF value at the eastern boundary which is set to zero here.

\section{Projected changes of dynamic height and specific volume anomaly}

Away from boundary current regions, horizontal gradients in DH are closely connected to circulation in the ocean interior where the geostrophic balance dominates such that geostrophic currents can be straightforwardly derived from the DH field. In the mean $20 \mathrm{c} 3 \mathrm{~m}$ RDH field over 1980-1999, the subtropical gyres can be easily identified by the relatively high RDH values in the low- to mid-latitudes (about $15-40^{\circ}$ ) from the surface to about $1,000 \mathrm{~m}$ in both hemispheres (Figs. 1, 2; also refer to Fig. 5c for the SSF). At the surface, the mean RDH is almost identical to the model mean DSL (Fig. 1a, d) over 1980-1999, with high spatial correlation of 0.99 between the two of them in the Pacific basin $\left(60^{\circ} \mathrm{S}-60^{\circ} \mathrm{N}, 120^{\circ} \mathrm{E}-80^{\circ} \mathrm{W}\right)$. The model mean $\mathrm{RDH}$ at the surface is also highly correlated (spatial correlation 0.98) with the observation-based mean dynamical topography (Maximenko et al. 2009; Figure is not shown, and data are available from http://apdrc.soest.hawaii.edu/ projects/DOT). High RDH values can be found in the centres of subtropical gyres. There are relatively strong (weak) zonal slopes in the west (east), which is consistent with the strong and narrow poleward western boundary currents in the west, and slow and wide equatorward flow in the interior of the basin. The subtropical gyres weaken with increasing depth and their cores also tend to move poleward (Qu 2002; Roemmich et al. 2007; Figs. 1, 2).

For the future climate change projection under the SRES A1B scenario, the RDH changes at the surface for 2080-2099 relative to 1980-1999 (hereafter referred to as the "SRESA1B-20c3m" change) resembles the DSL changes over the same period (spatial correlation of 0.96 in the Pacific basin $60^{\circ} \mathrm{S}-60^{\circ} \mathrm{N}, 120^{\circ} \mathrm{E}-80^{\circ} \mathrm{W}$ ). Therefore the $\mathrm{RDH}$ at the sea surface is a good substitute for the DSL and closely represents both the mean distributions under current climate and change distributions during future climate (Fig. 1a, d show the spatial distributions of both the mean and SRESA1B-20c3m change). However, the contribution from density changes in the deep ocean below the reference layer as used in RDH calculation and other processes changing the water-column mass (e.g., mass redistribution) could explain small differences between DSL and RDH at the surface. Under future climate change, positive RDH changes (SRESA1B-20c3m) can be found at the poleward edges of both subtropical gyres in the Pacific upper ocean. In other words, subtropical gyres are projected to expand poleward in both hemispheres (Figs. 1a, b, d and 2a), which is consistent with the finding by Saenko et al. (2005) based on the Canadian Centre for Climate Modeling and Analysis (CCCMA) AOGCM and is also in agreement with recent finding by $\mathrm{Wu}$ et al. (2012) who found enhanced warming over subtropical western boundary currents associated with poleward shift and or intensification of subtropical gyres. However, the poleward expansion of subtropical gyres has different vertical distributions in the SPac and NPac. Negative RDH changes (SRESA1B$20 \mathrm{c} 3 \mathrm{~m})$ are projected for the subsurface NPac from the main thermocline around $400 \mathrm{~m}$ to at least $2,000 \mathrm{~m}$ over the latitudinal range of about $20-45^{\circ} \mathrm{N}$ (Figs. 1c, f and 2a), which implies that the subtropical gyre circulation is projected to spin down in the subsurface NPac. In terms of the $\mathrm{RDH}$ meridional gradient from the gyre centre to the poleward edge at $600 \mathrm{~m}$, the spin-down is about $20 \%$ of the current-day value over 1980-1999 (refer to Fig. 1f). In contrast, in the SPac positive RDH changes (SRESA1B$20 \mathrm{c} 3 \mathrm{~m}$ ) are projected to occur at the poleward edge of subtropical gyre $\left(35-50^{\circ} \mathrm{S}\right)$ from the surface to at least 2,000 $\mathrm{m}$ and imply a corresponding spin-up of about $25 \%$ (refer to Fig. 1f). Thus the vertical structure of RDH changes in the SPac is much more barotropic rather than the baroclinic response projected for the NPac (Figs. 1e, $\mathrm{f}$ and $2 a)$.

Multi-model ensemble averaging is commonly used for future climate projection as shown in Figs. 1 and 2. But we would also like to know whether those distributional features found in ensemble means also appear in most of climate models. In other words, do the majority of individual models shares the similar distributional features and agree with the ensemble mean? By examining projection of RDH changes in individual models (refer to supplementary figures S1-S3, and Table 2), we found 9 out of the 11 models agree with ensemble mean, either for the meridional-vertical distribution (Fig. S1) or for the spatial distribution at $100 \mathrm{~m}$ (Fig. S2) and $600 \mathrm{~m}$ (Fig. S3). Two outlier models, FGOALS-g1.0 and UKMO-HADCM3 (refer to Table 2), both differ significantly from the ensemble mean at and beyond the poleward edge of subtropical gyre in the SPac. FGOALS-g1.0 model doesn't project the barotropic distribution of positive RDH changes at the poleward edge around $50^{\circ} \mathrm{S}$. While in UKMO-Had$\mathrm{CM} 3$ projection, the $\mathrm{RDH}$ changes reduce the meridional 
gradient of mean RDH over $40-60^{\circ} \mathrm{S}$, rather than enhance it as in the ensemble mean (refer to last two panels in Fig. $\mathrm{S} 1$ ). Due to the agreement among the majority of available CMIP3 models, we are confident that the multiple-model ensemble mean does show some common and robust features for future changes, thus we will mainly focus on ensemble means in this study.

This asymmetric distribution of the subtropical gyre changes (more barotropic in the SPac vs. baroclinic in the $\mathrm{NPac}$ ) is closely related to the thermosteric contribution, i.e., temperature field changes (compare $\Delta D$ and $\Delta D_{T}$ in Fig. 2a, b, and $\delta$ and $\delta_{T}$ in Fig. 2e, f). Thermal expansion is an important factor to cause global sea level rise, and the global mean thermal expansion is projected to be 13-32 cm under the SRES A1B for the last decade of the twenty-first century compared with the 1980-1999 period (Meehl et al. 2007; also refer to Fig. 3). For future climate change forced with increasing concentrations of GHGs, the ocean is generally projected to warm more in the upper ocean, and the warming decreases with depth (refer to the red curve in Fig. 3b). However, thermal expansion in the NPac subtropical gyre region is projected to be stronger than the global average for the upper ocean above $500 \mathrm{~m}$, and slightly weaker for the subsurface below $500 \mathrm{~m}$ (compare red and black curves in Fig. 3b; Note Fig. 3a-c show the averages over $35-45^{\circ} \mathrm{N}$, and averaging over wider meridional range over $20-45^{\circ} \mathrm{N}$ results in similar results). Such vertical distribution of thermal expansion, i.e., stronger (weaker) warming above (below) $500 \mathrm{~m}$, implies a more stratified ocean in this region (Yin et al. 2010; Xu et al. 2011; Also see Figs. 2e, f and 3a, b). In contrast, in the poleward edge of the SPac subtropical gyre, the thermal expansion is uniformly stronger than the global average except the upper $100 \mathrm{~m}$ (Fig. 3e).

Table 2 Correlation of dynamic height distribution between each model and the multi-model average as shown in Figs. S1 (meridionalvertical section), S2 (100 m depth) and S3 (600 m depth)

\begin{tabular}{llll}
\hline Model & $\begin{array}{l}\text { Correlation } \\
\text { Fig. S1 }\end{array}$ & $\begin{array}{l}\text { Correlation } \\
\text { Fig. S2 }\end{array}$ & $\begin{array}{l}\text { Correlation } \\
\text { Fig. S3 }\end{array}$ \\
\hline BCCR-BCM2.0 & 0.67 & 0.65 & 0.69 \\
CGCM3.1(T63) & 0.90 & 0.69 & 0.82 \\
CNRM-CM3 & 0.66 & 0.76 & 0.68 \\
CSIRO-MK3.5 & 0.85 & 0.72 & 0.83 \\
ECHO-G & 0.77 & 0.73 & 0.89 \\
FGOALS-g1.0 & $\underline{0.33}$ & $\underline{0.14}$ & 0.53 \\
GFDL-CM2.0 & 0.83 & 0.82 & 0.84 \\
GFDL-CM2.1 & 0.91 & 0.75 & 0.86 \\
MIROC3.2 (medres) & 0.94 & 0.89 & 0.88 \\
MRI-CGCM2.3.2 & 0.65 & 0.73 & 0.78 \\
UKMO-HADCM3 & $\underline{0.41}$ & $\underline{0.46}$ & 0.48 \\
\hline
\end{tabular}

Low correlation coefficients $(<0.5)$ are underscored
In addition, the Pacific Ocean, except in those evaporation-dominant regions, is projected to be fresher, thus halosteric impacts generally contribute to higher RDH changes for most regions in the Pacific (Fig. 2c, g), which is caused by both the global hydrological cycle change and ocean circulation (especially the Atlantic Meridional Overturning Circulation) change (e.g., Yin et al. 2010). The global average of $\delta_{H}$ is near zero, thus without significant fresh water input from land ice melting and lowering of the global mean salinity, its contribution to global mean sea level is negligible (red curve in Fig. 3c). In other words, saline contraction, unlike thermal expansion, doesn't contribute much to the global mean sea level change (e.g., Lowe and Gregory 2006; Yin et al. 2010). The halosteric contribution, associated with the redistribution of salt within the global ocean, can nonetheless have comparable impacts on regional distributions of RDH and DSL as the thermosteric contribution (e.g., Lowe and Gregory 2006; Landerer et al. 2007; Yin et al. 2010). For the poleward edge region of the NPac subtropical gyre, freshening salinity change, i.e., positive $\delta_{H}$ change, induces positive $\mathrm{RDH}$ changes and also enhances the stronger upper ocean stratification associated with thermal expansion (Fig. 3c; also refer to Fig. 8 of Landerer et al. 2007), though the vertical structure of both $\delta$ and RDH changes are mainly determined by the thermosteric contribution (Figs. 2 and 3 ). This dominance of the thermosteric contribution is consistent with Pardaens et al. (2011), see their Fig. 4). Fresher and warmer changes in the subtropical NPac region are consistent with findings by Lee (2009) and Xu et al. (2011) on subtropical model water formation based on the GFDL CM2.1 model. Stronger halosteric contribution associated with fresher salinity change can be found in the poleward edge of the SPac subtropical gyre than in the Npac subtropical gyre (Figs. 2c, 3c,f).

\section{Possible underlying mechanisms}

As revealed by Eqs. 2-4, the DH changes can be determined directly by local temperature and salinity changes. Thus, any physical processes affecting temperature and salinity (or density which combines both of them) change the dynamic topography and ocean circulation which further change the distribution of temperature and salinity. That is, the density changes are dynamically coupled with circulation changes, and are also linked either directly or indirectly with changes in the air-sea fluxes of momentum, heat and freshwater related to atmospheric changes (e.g., Meehl et al. 2007; Timmermann et al. 2010).

For the SRES A1B scenario of increasing GHGs, the ocean is projected to warm, with the strongest warming usually at the surface (refer to Fig. 10.7 of Meehl et al. 
Specific Volume Anomaly $\left(10^{-4} \mathrm{~m}^{3} \mathrm{~kg}^{-1}\right)$ and Dynamic height (dyn $\mathrm{cm}$ ) Changes (SRESA1B - 20c3m)

(a) Steric

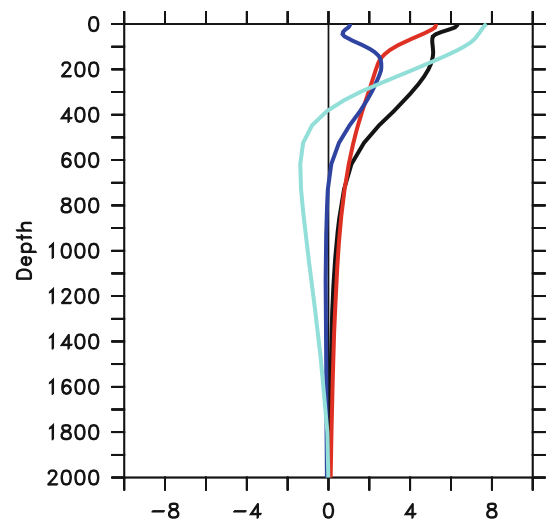

(d) Steric

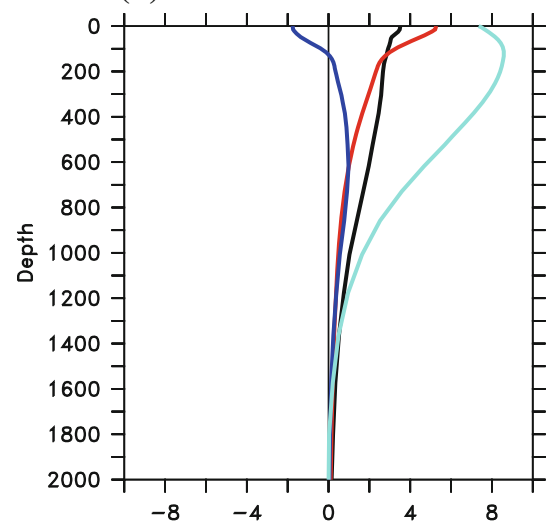

(b) Thermosteric

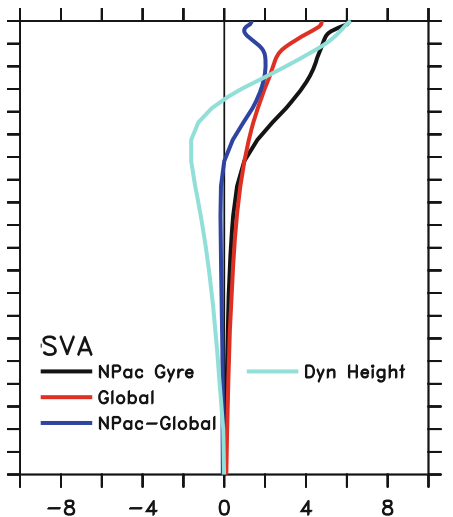

(e) Thermosteric

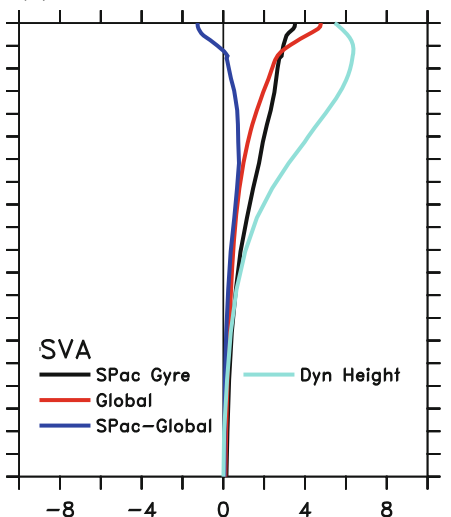

(c) Halosteric

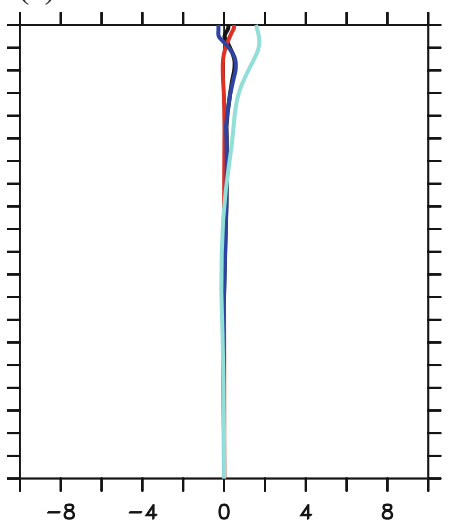

(f) Halosteric

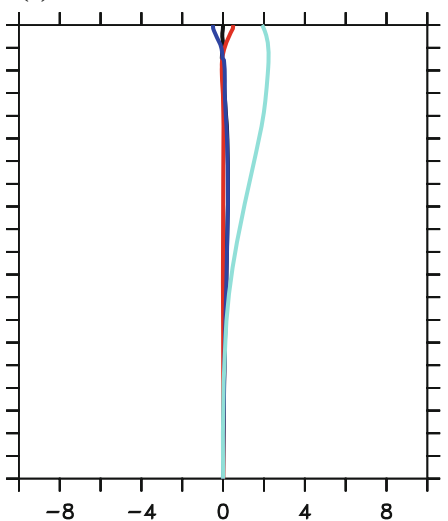

Fig. 3 Vertical distributions of a specific volume anomaly change and dynamic height change under the SRES A1B scenario (SRESA1B-20c3m) during 2080-2099 relative to 1980-1999, and its b thermosteric and $\mathbf{c}$ halosteric components averaged over the western part of poleward flank of the North Pacific subtropical gyre $\left(180-160^{\circ} \mathrm{W}, 35-45^{\circ} \mathrm{N}\right)$. Both global (red curve) and regional (black curve) averages of specific volume anomaly change are shown, with their differences (i.e., regional deviations from global mean) also plotted (blue curve). In each panel, the dynamic height change (cyan curve) is the vertical integration of specific volume anomaly change (blue curve, refer to Eqs. 2-4). d-f Same as (a-c), but for the western part of poleward flank of the South Pacific subtropical gyre $\left(180^{\circ}-\right.$ $\left.160^{\circ} \mathrm{W}, 40^{\circ}-50^{\circ} \mathrm{S}\right)$
Fig. 4 The multi-model average of sea surface temperature change $\left({ }^{\circ} \mathrm{C}\right)$ (SRESA1B-20c3m) over 2080-2099 relative to 1980-1999

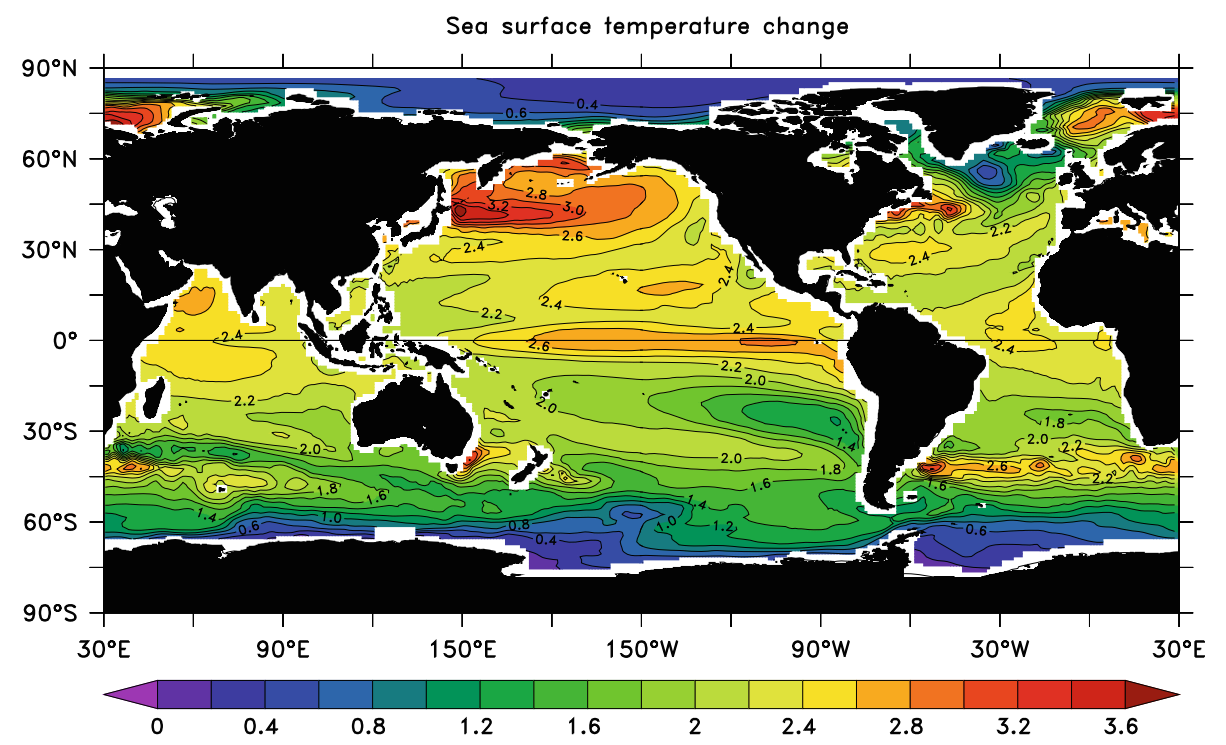


2007). The SST in the NPac (especially the subtropical gyre region) is projected to warm more than the global average (Fig. 4). In particular, the Kuroshio extension (KE) region is projected to have strong SST warming $\left(>3{ }^{\circ} \mathrm{C}\right)$ over 2080-2099 relative to 1980-1999. The spatial distribution of SST changes as shown in Fig. 4 is in good agreement with the analyses by Capotondi et al. (2012) and Xie et al. (2010). Density surfaces with a neutral density greater than about $26.2 \mathrm{~kg} \mathrm{~m}^{-3}$ do not outcrop in the NPac and instead these surfaces are ventilated from the southern hemisphere (Hanawa and Talley 2001). As discussed in Sect. 3, stronger surface warming (with the help of fresher salinity change) in the upper ocean in the NPac subtropical gyre region makes the ocean more stratified (Fig. 3), reinforcing the difficulty of the upper ocean warming penetrating to depth and accentuating the upper ocean warming. This strong surface-intensified warming projected in the KE region (Fig. 4) may be related to the poleward expansion of the KE, and can also be partially caused by decreased upward net surface heat flux induced by decreased air-sea temperature differences ( $\mathrm{Xu}$ et al. 2011).

In contrast, the warming of SST in the SPac subtropical gyre region is slightly less than the global mean in mid latitudes and well below the global average south of $45^{\circ} \mathrm{S}$ (refer to Figs. 2f, 4). However, the warming penetrates much more deeply than in the NPac, to at least 2,000 m at the poleward edge of the subtropical gyre over $40-50^{\circ} \mathrm{S}$ (Figs. 2f, 3e). This nearly top-to-bottom warming pattern has already taken place as discussed by Gille (2008) and Cai et al. (2010), both of whom found a maximum in the oceanic heat content build-up in the $35-50^{\circ} \mathrm{S}$ latitude band over the past $\sim 50$ years. Cai et al. (2010) further pointed out that such ocean warming cannot be explained by local heat flux changes.

Changes of surface freshwater flux can cause ocean salinity changes, especially the sea surface salinity (SSS) changes. Based on in situ hydrographic measurements over 1950-2008, Durack and Wijffels (2010) found that the spatial pattern of SSS change over $50+$ years resembles that of the mean SSS, suggesting a connection between SSS changes and freshwater flux changes, and also impling an amplified global hydrological cycle, i.e., a "wet-getwetter and dry-get-drier" situation in a warming climate (e.g., Held and Soden 2006; Lagerloef et al. 2010; Durack et al. 2012). These findings for the historical period also hold well for future climate projection, as shown by Capotondi et al. (2012) based on 10 CMIP3 models. However, the subsurface salinity changes are not necessarily associated with local freshwater flux. For example, Durack and Wijffels (2010) pointed out that to first order the poleward migration of isopycnal outcrops, induced by broad scale global surface warming, drives a pattern of subsurface isopycnal salinity changes, i.e., freshening of the central waters on isopycnals (between the shallow subtropical salinity maxima and intermediate water salinity minima) and increases of salinity in the subtropical waters (above the shallow thermocline). The other interesting feature about salinity change under global warming is that the inter-basin salinity difference between the Atlantic and Pacific tend to be enhanced with saltier Atlantic and fresher Pacific (Landerer et al. 2007; Durack and Wijffels 2010; Yin et al. 2010), in agreement with what we found based on the CMIP3 ensemble average (Figure not shown).

Wind stress changes significantly affect the RDH, ocean circulation and the DSL (Lowe and Gregory 2006; Timmermann et al. 2010; Suzuki and Ishii 2011). The large-scale meridional atmospheric circulation (i.e., the Hadley cell), and the subtropical highs of sea level pressure (SLP) are projected to expand poleward (e.g., Meehl et al. 2007; Lu et al. 2007; Seidel et al. 2008; Johanson and Fu, 2009; Fig. 5a). For most mid-latitude regions in the SPac, the SLP is projected to increase with a peak around $135^{\circ} \mathrm{W}$, $45^{\circ} \mathrm{S}$, southwest of the current day mean subtropical high located around $95^{\circ} \mathrm{W}, 30^{\circ} \mathrm{S}$ (Fig. 5a). In the NPac, there is a southwest-northeast tilting band of positive SLP changes extending roughly from Japan to Alaska, with the peak change being located at $165^{\circ} \mathrm{W}, 45^{\circ} \mathrm{N}$ (Fig. 5a). Off the equator, sea surface wind changes are generally in geostrophic balance with SLP changes (Holton 1992). Consequently strong anticyclonic (cyclonic) wind stress curl changes can be found between $35^{\circ}$ and $50^{\circ} \mathrm{S}$ (south of $55^{\circ} \mathrm{S}$ ) in the SPac (Fig. 5b). There is a dipolar structure of wind stress curl changes in the western part of the NPac, with anticyclonic (cyclonic) curl between $30^{\circ}$ and $55^{\circ} \mathrm{N}$ (between $10^{\circ}$ and $30^{\circ} \mathrm{N}$ ). For the large-scale ocean circulation, the zonal wind stress and wind stress curl are two critical parameters (the wind stress curl is primarily determined by the meridional gradient of zonal wind stress). A poleward shift of mid-latitude westerlies is projected for both the NPac and the SPac, with the shift in the southern hemisphere being stronger (Fig. 6). In addition to the poleward shift, the westerly winds also intensify in the SPac. Consequently the latitude of peak westerlies, or equivalently the latitude of zero wind stress curl, shifts southward by about $2^{\circ}$ in the SPac (Fig. 6). In contrast, the intensification is not very obvious in the NPac. The expansion of the Hadley cell cannot explain all wind stress changes discussed above, especially for mid-to-high latitudes where other process such as the Southern Annular Mode (SAM, Kwok and Comiso 2002) can also play roles.

The Sverdrup balance provides a simple connection between surface wind forcing and large-scale ocean circulation. In the mean current climate represented by the $20 \mathrm{c} 3 \mathrm{~m}$ runs, the large-scale ocean gyre circulation can be clearly identified, consistent with large-scale wind stress 
curl forcing. The subtropical gyres are depicted by positive (negative) SSF values in the low- to mid-latitudes in the NPac (Spac) (Fig. 5c). Under the projected climate change of the poleward expansion of the Hadley cell and midlatitude westerly winds, the Sverdrup balance will induce a poleward expansion of the subtropical ocean gyres (Figs. 5b, c, 6). The NPac subtropical gyre interior is projected to spin down slightly between $15^{\circ}$ and $35^{\circ} \mathrm{N}$ (Fig. 5c), as a result of relatively weak cyclonic wind stress curl changes (Figs. 5b, 6a). Such weak spin-down indicated by the SSF changes which are derived solely from surface wind stress changes (Fig. 5c) is also in agreement with negative values of the depth-integrated steric height (DISH) changes (Fig. 5d), mainly associated with negative DH changes and spin-down of the gyre circulation in the subsurface ocean (Figs. 1e, f, 2a). East of Japan, the KE separates the subtropical and subpolar gyres. Anticyclonic wind stress curl changes in the KE region cause the Kuroshio recirculation gyre to spin up. However, the spin-up only appears in the upper several hundred meters (Figs. 1a-d, 2a) and is not strongly reflected in both SSF and DISH changes (Fig. 5c, d). There is no obvious spindown of the SPac subtropical gyre interior as in the northern hemisphere. The broad-scale anticyclonic wind stress curl changes associated with strengthening of southeasterly trade winds and mid-latitude westerly, drive

(a) Sea level pressure change

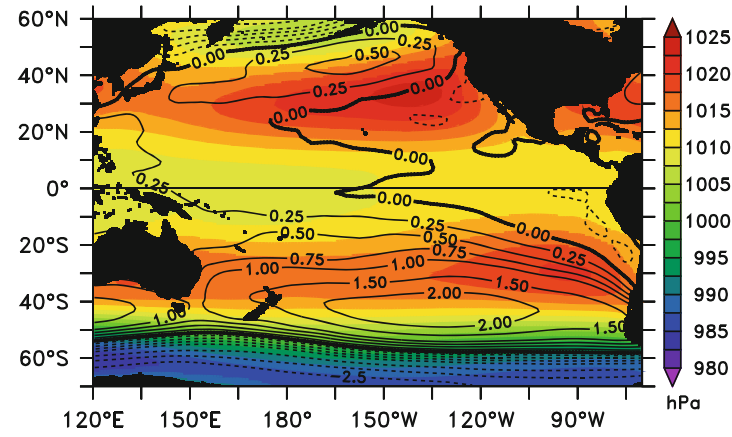

(c) Sverdrup stream function change

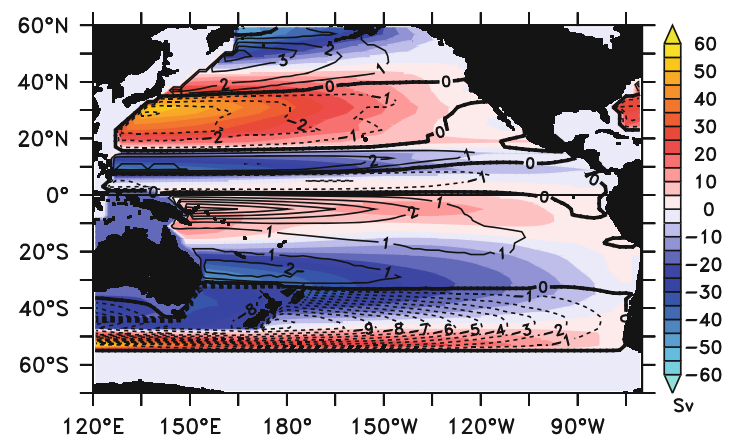

Fig. 5 The SRESA1B-20c3m changes of a sea level pressure (in hPa, contours), b wind stress (arrow) and curl (in $1 \times 10^{-8} \mathrm{Nm}^{-3}$, shading), c Sverdrup stream function (in Sv, contours) and d depth- the SPac subtropical gyre to expand and intensify poleward with peak SSF change of $-11 \mathrm{~Sv}$ east of New Zealand (Fig. 5c). Similarly a zonal band of positive DISH changes can also be found, extending eastward from New Zealand and almost reaching the eastern boundary (Fig. 5d).

Anticyclonic wind stress curl changes can be found in the poleward edges of both subtropical gyres, but why are the vertical distributions of RDH and ocean circulation so different? The difference can be partially explained by the spatial distribution of wind stress curl changes. The wind stress curl changes often result in westward intensification of both SSF and DISH changes (Fig. 5c, d). Along $45^{\circ} \mathrm{S}$, coherent and strong anticyclonic wind stress curl changes across the whole basin lead to penetration of positive RDH changes increasing westward from the eastern boundary (Fig. 7). Heat content change also increases westward at this latitude (Cai et al. 2010). In contrast, along $35^{\circ} \mathrm{N}$, the section east (west) of $160^{\circ} \mathrm{W}$ is projected to have cyclonic (anticyclonic) wind stress curl changes, and the curl changes are also weaker. Therefore, the westward intensification of RDH increases is much shallower and is confined to the western half basin at the poleward edge of the NPac subtropical gyre (Fig. 7).

This wind-driven response in the KE region is consistent with Sakamoto et al. (2005) who argued that the Kuroshio

(b) Wind stress (arrow) and curl (shading) change

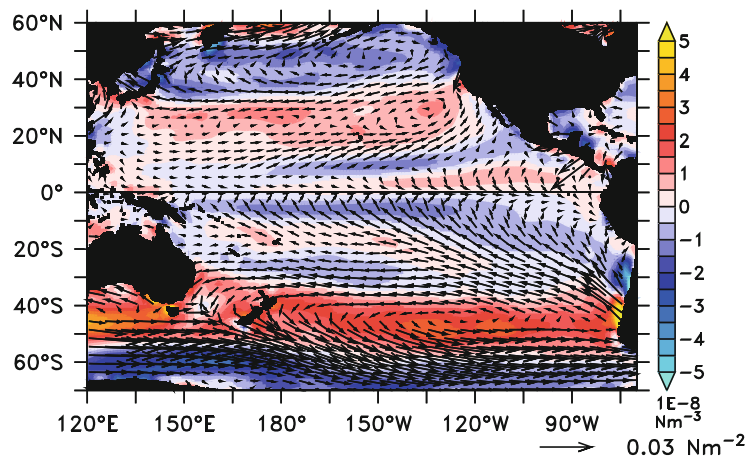

(d) Depth-Integrated Steric Height (DISH) change

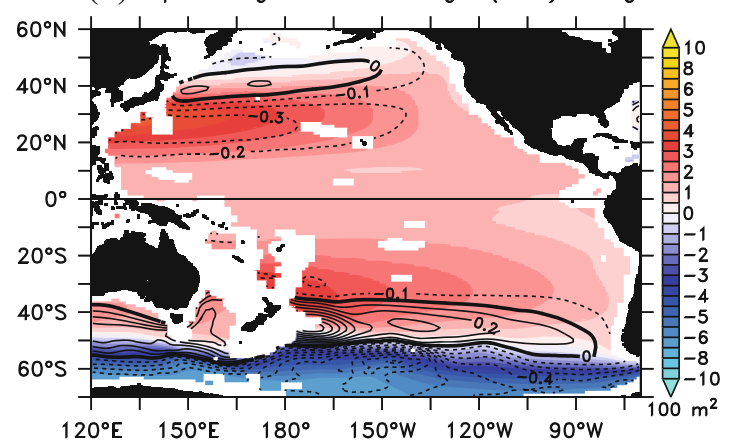

integrated steric height (in $1 \times 10^{2} \mathrm{~m}^{2}$, contours) over 2080-2099 relative to $1980-1999$. Mean distributions from $20 \mathrm{c} 3 \mathrm{~m}$ runs during 1980-1999 are shown by shading in panels (a, c, d) 
(a) Zonal average of wind stress curl

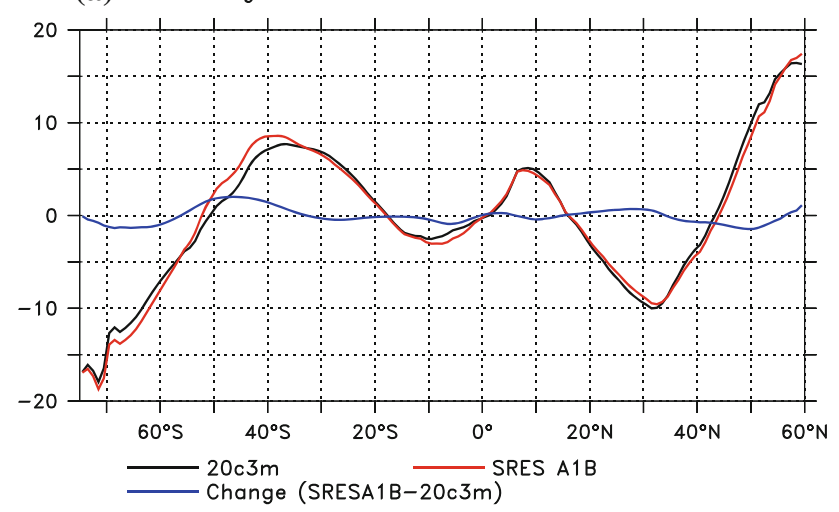

(b) Zonal average of zonal wind stress

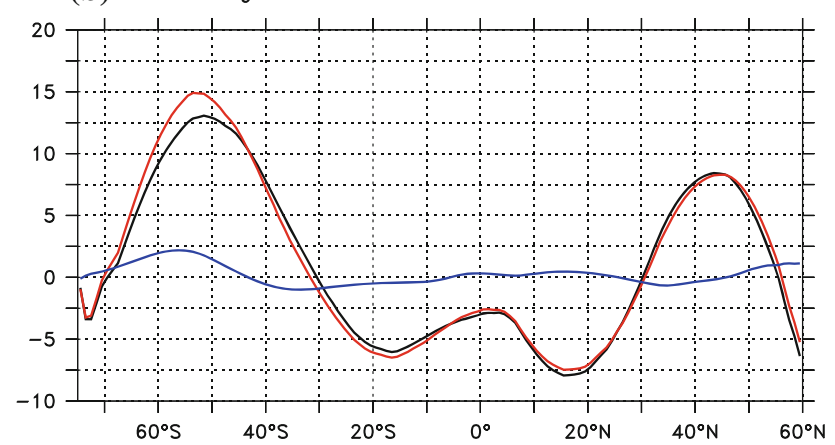

Fig. 6 a Zonal average of wind stress curl (in $1 \times 10^{-8} \mathrm{Nm}^{-3}$ ) over the Pacific basin from 20c3m runs during 1980-1999 (black curve), SRES A1B runs during 2080-2099 (red curve), and changes between the two of them (SRESA1B-20c3m, blue curve), derived from 11 CMIP3 modes. b Same as (a) but for zonal wind stress (in $1 \times 10^{-2} \mathrm{Nm}^{-2}$ )

and KE would accelerate because of the recirculation gyre spin-up driven by the anticyclonic wind stress curl changes east of Japan (see their Fig. 3) when forced with increasing $\mathrm{CO}_{2}$ concentration. However, the baroclinic distribution of NPac subtropical gyre changes was not disclosed in their study. Also Yin et al. (2010) argued that the high sea level rise east of Japan (refer to Fig. 1a, d) is mainly due to the poleward expansion rather than the strengthening of the subtropical gyre (Figs. 2a, 5c, d). In fact, the multi-model average of 11 CMIP3 models suggests that most of the NPac subtropical gyre is projected to spin down slightly (Fig. 5c, d). The spin-down, if measured by the decrease of the maximum SSF value in the subtropical gyre, is about $8 \%$, from $52 \mathrm{~Sv}$ under the current climate to $48 \mathrm{~Sv}$ under projected climate change.

In conclusion, surface wind stress changes play significant roles in the distributions of the RDH and DSL, and in the asymmetry of the vertical distribution of RDH in the subtropical gyres in the Pacific. However, both surface heat flux and freshwater fluxes also have non-negligible impacts. Moreover, different regions have different underlying mechanisms which are summarized below:
1. The poleward edge of the NPac subtropical gyre (about $35^{\circ}-45^{\circ} \mathrm{N}$ ): This region is projected to experience anticyclonic wind stress curl change. Such wind curl stress forcing has two immediate effects: to spin up the Kuroshio recirculation gyre and to deepen the isopycnal surfaces, both of which contribute to positive RDH changes in the upper ocean, with the second factor being dominant. In addition, net surface heat flux changes also induce strong upper ocean warming and positive RDH changes.

2. The NPac subtropical gyre interior (about $15^{\circ}-35^{\circ} \mathrm{N}$ ): the broad cyclonic wind stress changes slightly weaken the subtropical gyre circulation by about $4 \mathrm{~Sv}$. The cyclonic wind stress curl changes will also induce upward Ekman pumping velocity changes and thus reduce the mean Ekman downwelling in this region. Such a baroclinic response can partially explain the weak subsurface warming. Positive net heat flux changes induce strong upper ocean warming which, together with some contribution from the fresher salinity changes, leads to stronger stratification in this region.

3. The SPac subtropical gyre interior $\left(15^{\circ}-40^{\circ} \mathrm{S}\right)$ : There is no significant change in the SPac subtropical gyre interior (Figs. 2a, 5c, d), unlike its counterpart in the NPac, partially due to the non-significant coherent wind stress changes there (Figs. 5b, 6). The thermosteric contributions to $\delta$ and $\mathrm{RDH}$ tend to compensate the halosteric contributions (Fig. 2b, c, f, g). However, our current finding based on 11 CMIP3 models is different from Saenko et al. (2005) who found similar slow-down of the subtropical gyre interior in both SPac and NPac based on model simulation from the CCCMA AOGCM, consistent with their model's basin-scale wind stress changes (see their Fig. 7).

4. The poleward edge of the SPac subtropical gyre (about $40-50^{\circ} \mathrm{S}$ ): the strong anti-cyclonic wind stress curl change pattern causes the Supergyre (e.g., Ridgway and Dunn 2007) to spin up, and the SPac subtropical gyre to expand and intensify poleward. There is a significant barotropic component in the DSL changes, or equivalently the RDH changes at the surface. The enhanced downward Ekman pumping associated with anti-cyclonic wind stress curl changes helps to transfer heat to the deep ocean. The local net surface heat flux changes cannot explain strong subsurface warming.

\section{Discussion and conclusions}

We analysed the projection of sea level, dynamic height and ocean circulation and related atmospheric states of 11 
Latitude $35^{\circ} \mathrm{N}$

(a) Wind stress curl change

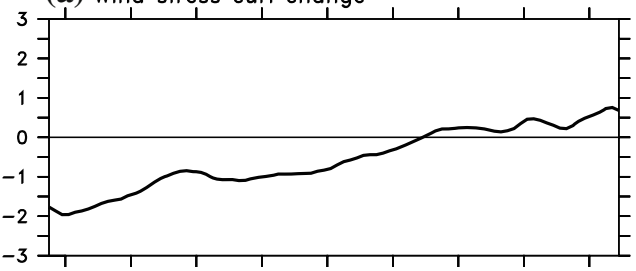

(c) Streamfunction and DISH changes

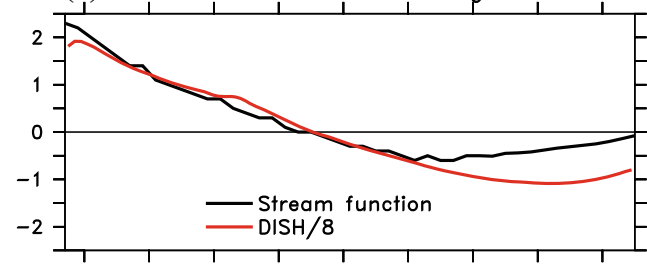

(e) Dynamic height change

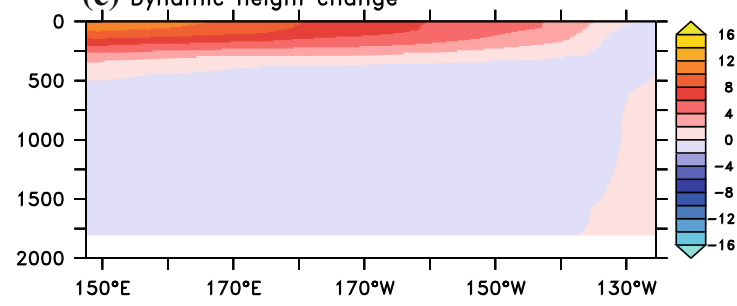

Fig. 7 Left (right) panels show the SRESA1B-20c3m changes at $35^{\circ} \mathrm{N}\left(45^{\circ} \mathrm{S}\right)$ for $\mathbf{a}, \mathbf{b}$ Wind stress curl (in $\left.1 \times 10^{-8} \mathrm{Nm}^{-3}\right), \mathbf{c}, \mathbf{d}$ the Sverdrup stream function (in Sv, black line) and depth-integrated steric height (in $100 \mathrm{~m}^{2}$, red line, scaled with a factor of $1 / 8$ in plotting) and e, f dynamic height (in dynamic centimetres with reference to 2,000 db) during 2080-2099 relative to 1980-1999,

CMIP3 climate models under the SRES A1B scenario. Based on changes of sea level and dynamic height (referenced to 2,000 db), poleward expansion of the subtropical gyre circulation in the upper ocean is projected for both the SPac and NPac. The subtropical gyre circulation is projected to spin down by about $20 \%$ in the subsurface NPac, while the subtropical gyre circulation in the SPac is projected to strengthen by about $25 \%$ and expand poleward in the subsurface SPac.

The asymmetry in the vertical distribution of dynamic height and ocean circulation between the NPac and SPac subtropical gyres identified here is consistent with Suzuki and Ishii (2011) who studied the regional distribution of sea level changes by decomposing sea level change into barotropic and various baroclinic modes. Based on the MIROC 3.2 model, they found that the barotropic component of sea level changes is mainly significant in the Southern Ocean including the poleward edge of the SPac subtropical gyre (see their Fig. 2), and that the baroclinic component (especially associated with the first baroclinic mode) of sea level changes is dominant in the NPac subtropical gyre (see their Figs. 2, 3).

Roemmich et al. (2007) found a decadal spin-up of the SPac subtropical gyre during the 1990s, based on altimeter, hydrographic and float data. The spin-up is found to be
Latitude $45^{\circ} \mathrm{S}$

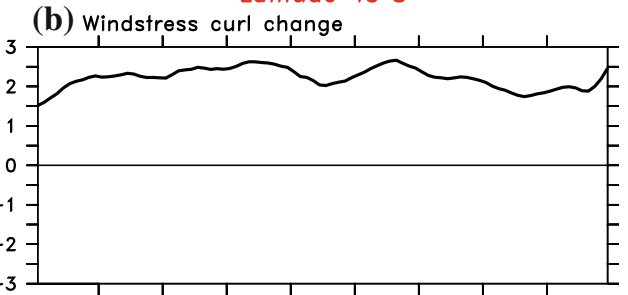

(d) Streamfunction and DISH changes

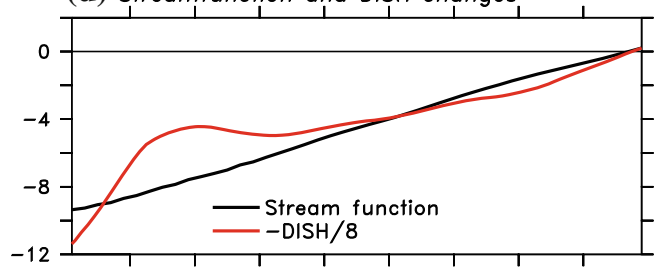

(f) Dynamic height change

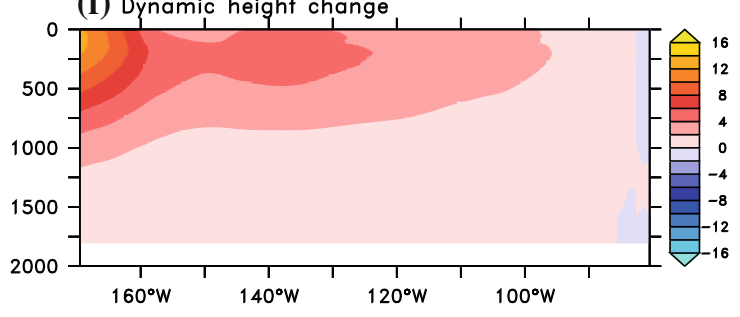

derived from 11 available CMIP3 models. Dynamic height changes at the eastern boundary along $35^{\circ} \mathrm{N}$ are removed from panel (e) to better show the longitudinal changes with reference to the eastern boundary, similarly eastern boundary values along $45^{\circ} \mathrm{S}$ are also removed from panel (f)

related to the deepening of isopycnal surfaces, extending from the surface to at least $1,800 \mathrm{~m}$. They further suggested that the gyre spin-up should be driven by SLP and wind stress curl changes associated with the SAM. However, they also mentioned that it's hard to distinguish the anthropogenic climate change signal from natural climate variability, partially because the SAM may also change in response to climate change. The mechanism identified here for the SPac subtropical gyre change is consistent with Roemmich et al.'s previous work based on observational data. Similarly, based on 17 CMIP3 climate models, Cai et al. (2010) identified fast warming and heat content increase in the $35^{\circ}-50^{\circ} \mathrm{S}$ latitude band during 1951-1999. The deep-reaching fast warming can be favourably explained by the Sverdrup-type response to wind stress changes. Nonetheless, some non-local heat gain south of $50^{\circ} \mathrm{S}$ is also required to explain the heat build-up in the $35^{\circ}-50^{\circ} \mathrm{S}$ latitude band. Though our discussion is mainly focusing on subtropical gyres, the projected poleward expansion of subtropical gyre in the SPac is also connected to projected changes further south, i.e., the Southern Ocean. The meridional gradient of sea level is also projected to strengthen in the Southern Ocean (refer to Fig. 1d; Bouttes et al. 2012). 
Sueyoshi and Yasuda (2012) recently discussed large sea level rise east of Japan and associated this rise with anti-cyclonic wind-stress curl change, based on 15 CMIP3 climate models under the SRES A1B scenario. Though the multi-model mean tends to suggest that the KE displays both a poleward shift and an intensification, there are significant inter-model differences in the KE responses (see their Fig. 4). That is, some models display only a northward shift without intensification, while the others tend to show only intensification without a northward shift. They further identified that differences in KE response are closely connected with differences in model representation of SLP and wind-stress changes in the North Pacific. Oshima et al. (2012) analysed 24 CMIP3 models and found significant inter-model differences of regional SLP changes closely connected with different responses of the Aleutian Low. However, these inter-model differences mainly induce uncertainty in subpolar regions, while here we focus on subtropical gyres.

In Sect. 4, we found changes of subtropical gyre circulation and sea level by analysing multi-model averages of output fields and then we proposed underlying mechanisms by examining multi-model averages of forcing fields. This approach should be generally used with caution since there is no guarantee that the ensemble mean outputs (like dynamic height) should be dynamically in balance with ensemble mean forcings (like wind stress). However, wind plays significant roles in current study. For the wind-driven responses, either the Sverdrup-type response or the long Rossby wave dynamics are in principle linear. Thus, our approach by examining ensemble mean forcing fields is applicable to our current study.

We reported subtropical gyre circulation changes and related sea level changes under a future climate change scenario in the Pacific based on CMIP3 climate models. The new CMIP5 climate models (http://cmip-pcmdi.llnl. gov/cmip5/) are currently under analysis to see whether such asymmetric distributional feature can still be identified. Though CMIP3 models were regarded as the last generation of "state-of-the-art" climate models, many findings derived from CMIP3 models still hold well. What's more, CMIP3 models are still being actively analysed, sometimes with an aim to find the similarities and differences between CMIP3 and CMIP5 models. For example, Yin (2012) identified notable common features of sea level projection between CMIP3 and CMIP5 models, and concluded that many robust features exists across generations of climate models and emission scenarios. Similarly, we also examined $20+$ CMIP5 models and found similar regional distribution of dynamic sea level in the Pacific as in CMIP3 models (see Fig. S4), though examination of subsurface distributions of specific volume anomaly and dynamic height are ongoing. We plan to do further testing either with a layer model (such as Luyten et al. 1983) or an ocean general circulation model to verify the various underlying mechanisms proposed in this study.

Acknowledgments The authors would like thank Jonathan Gregory for helpful discussions. Detailed comments on early draft by Steven E. George helped to improve the manuscript. Critical reviews from two anonymous reviewers also improved the manuscript. We acknowledge the modeling groups, the Program for Climate Model Diagnosis and Intercomparison (PCMDI) and the WCRP's Working Group on Coupled Modelling (WGCM) for their roles in making available the WCRP CMIP3 multi-model dataset. Support of this dataset is provided by the Office of Science, U.S. Department of Energy. We also wish to acknowledge use of the Ferret program (http://ferret.pmel.noaa.gov/Ferret/) for analysis and graphics in this paper. This work is supported by the Pacific Climate Change Science Program (PCCSP) and follow-up Pacific-Australia Climate Change Science and Adaptation Planning (PACCSAP) Program administered by the Australian Department of Climate Change and Energy Efficiency (DCCEE) in collaboration with AusAID.

Open Access This article is distributed under the terms of the Creative Commons Attribution License which permits any use, distribution, and reproduction in any medium, provided the original author(s) and the source are credited.

\section{References}

Bouttes N, Gregory JM, Kuhlbrodt T, Suzuki T (2012) The effect of windstress change on future sea level change in the Southern Ocean. Geophys Res Lett 39:L23602. doi:10.1029/2012GL054207

Cai W, Cowan T, Godfrey S, Wijffels S (2010) Simulation of processes associated with the fast warming rate of the southern midlatitude ocean. J Clim 23:197-206

Capotondi A, Alexander MA, Bond NA, Curchitser EN, Scott JD (2012) Enhanced upper ocean stratification with climate change in the CMIP3 models. J Geophys Res 117:C04031. doi:10.1029/ 2011JC007409

Church JA et al (2010) Ocean temperature and salinity contributions to global and regional sea level change. In: Church JA, Woodworth PL, Aarup T, Wilson WS (eds) Understanding sea level rise and variability. Blackwell, New York, pp 143-176

Davis JL, Mitrovica JX (1996) Glacial isostatic adjustment and the anomalous tide gauge record of eastern North America. Nature 379:331-333

Delworth TL et al (2006) GFDL's CM2 global coupled climate models. Part I: formulation and simulation characteristics. J Clim 19:643-674

Deser C, Alexander MA, Timlin MS (1999) Evidence for a winddriven intensification of the Kuroshio current extension form the 1970s to the 1980s. J Clim 12:1697-1706

Durack PJ, Wijffels SE (2010) Fifty-year trends in global ocean salinities and their relationship to broad-scale warming. J Clim 23:4342-4362

Durack PJ, Wijffels SE, Matear RJ (2012) Ocean salinities reveal strong global water cycle intensification during 1950 to 2000 . Science 336:455-458

Gill AE (1980) Atmosphere-ocean dynamics. Academic Press, New York

Gille ST (2008) Decadal-scale temperature trends in the Southern Hemisphere Ocean. J Clim 21:4749-4765 
Gilson J, Roemmich D, Cornuelle B, Fu L-L (1998) Relationship of TOPEX/Poseidon altimetric height to steric height and circulation in the North Pacific. J Geophys Res 103:27947-27965

Hanawa K, Talley LD (2001) Mode waters. In: Siedler G, Church J, Gould J (eds) Ocean circulation and climate. International geophysics series, Academic Press, New York, pp 373-386

Hautala SL, Roemmich D, Schmitz WJ (1994) Is the North Pacific in Sverdrup balance along $24^{\circ} \mathrm{N}$ ? J Geophys Res 99:1604116052

Held IM, Soden BJ (2006) Robust responses of the hydrological cycle to global warming. J Clim 19:5686-5699

Holton JR (1992) An introduction to dynamic meteorology. Academic Press, New York, pp 507

Johanson CM, Fu Q (2009) Hadley cell widening: model simulations versus observations. J Clim 22:2713-2725

Kwok R, Comiso JC (2002) Spatial patterns of variability in Antarctic surface temperature: connections to the Southern Hemisphere Annular Mode and the Southern Oscillation. Geophys Res Lett 29:1705. doi:10.1029/2002GL015415

Lagerloef G, Schmitt R, Schanze J, Kao H-Y (2010) The ocean and the global water cycle. Oceanography 23:82-93

Landerer FW, Jungclaus JH, Marotzke J (2007) Regional dynamic and steric sea level change in response to the IPCC-A1B Scenario. J Phys Oceanogr 37:296-312

Lee H-C (2009) Impact of atmospheric CO2 doubling on the North Pacific Subtropical Mode Water. Geophys Res Lett 36:L06602. doi:10.1029/2008GL037075

Lowe JA, Gregory JM (2006) Understanding projections of sea level rise in a Hadley Centre coupled climate model. J Geophys Res 111:C11014. doi:10.1029/2005JC003421

Lu J, Vecchi GA, Reichler T (2007) Expansion of the Hadley cell under global warming. Geophys Res Lett 34:L06805. doi:10. 1029/2006GL028443

Luyten JR, Pedlosky J, Stommel H (1983) The ventilated thermocline. J Phys Oceanogr 13:293-309

Maximenko N, Niiler P, Centurioni L, Rio M-H, Melnichenko O, Chambers D, Zlotnicki V, Galperin B (2009) Mean dynamic topography of the ocean derived from satellite and drifting buoy data using three different techniques. J Atmos Oceanic Technol 26:1910-1919

Meehl G, Coauthors A (2007) Global climate projections. In: Solomon S et al (eds) Climate change 2007: the physical science basis. Cambridge University Press, Cambridge, pp 747-845

Nakicenovic N, Swart R (eds) (2000) Special report on emissions scenarios: a special report of Working Group III of the intergovernmental panel on climate change. Cambridge University Press, Cambridge

Oshima K, Tanimoto Y, Xie S-P (2012) Regional patterns of wintertime SLP change over the North Pacific and their uncertainty in CMIP3 multi-model projections. J Meteorol Soc Jpn 90A:386-396. doi:10.2151/jmsj.2012-A23

Pardaens AK, Gregory JM, Lowe JA (2011) A model study of factors influencing projected changes in regional sea level over the twenty-first century. Clim Dyn 36:2015-2033. doi:10.1007/ s00382-009-0738-x
Qu T (2002) Depth distribution of the subtropical gyre in the north Pacific. J Oceanogr 58:525-529

Randall DA et al (2007) Climate models and their evaluation. In: Solomon S et al (eds) Climate change 2007: the physical science basis. Cambridge University Press, Cambridge, pp 590-662

Ridgway KR, Dunn JR (2007) Observational evidence for a Southern Hemisphere oceanic supergyre. Geophys Res Lett 34:L13612. doi:10.1029/2007GL030392

Roemmich D, Gilson J, Davis R, Sutton P, Wijffels S, Riser S (2007) Decadal Spinup of the South Pacific Subtropical Gyre. J Phys Oceanogr 37:162-173

Saenko OA, Fyfe JC, England MH (2005) On the response of the oceanic wind-driven circulation to atmospheric $\mathrm{CO}_{2}$ increase. Clim Dyn 25:415-426

Sakamoto TT, Hasumi H, Ishii M, Emori S, Suzuki T, Nishimura T, Sumi A (2005) Responses of the Kuroshio and the Kuroshio Extension to global warming in a high-resolution climate model. Geophys Res Lett 32:L14617. doi:10.1029/2005GL023384

Seidel DJ, Fu Q, Randel WJ, Reichler TJ (2008) Widening of the tropical belt in a changing climate. Nat Geosci 1:21-24

Sen Gupta A, Muir L, Brown J, Phipps S, Durack P, Monselesan D, Wijffels S (2012) Climate drift in the CMIP3 models. J Clim. doi:10.1175/JCLI-D-11-00312.1

Sueyoshi M, Yasuda T (2012) Inter-model variability of projected sea level changes in the western North Pacific in CMIP3 coupled climate models. J Oceanogr. doi:10.1007/s10872-012-0117-9

Suzuki T, Ishii M (2011) Regional distribution of sea level changes resulting from enhanced greenhouse warming in the model for Interdisciplinary Research on Climate version 3.2. Geophys Res Lett 38:L02601. doi:10.1029/2010GL045693

Sverdrup HU (1947) Wind-driven currents in a baroclinic ocean: with application to the equatorial currents in the eastern Pacific. Proc Nat Acad Sci 33:318-326

Timmermann A, McGregor S, Jin F-F (2010) Wind effects on past and future regional sea level trends in the southern Indo-Pacific. J Clim 23:4429-4437

Wu L, Cai W, Zhang L, Nakamura H, Timmermann A, Joyce T, McPhaden MJ, Alexander M, Qiu B, Visbeck M, Chang P, Giese B (2012) Enhanced warming over the global subtropical western boundary currents. Nat Clim Change 2:161-166. doi:10.1038/ NCLIMATE1353

Xie S-P, Deser C, Vecchi GA, Ma J, Teng H, Wittenberg AT (2010) Global warming pattern formation: sea surface temperature and rainfall. J Clim 23:966-986

Xu L, Xie S-P, Liu Q, Kobashi F (2011) Response of the North Pacific subtropical countercurrent and its variability to global warming. J Oceanogr. doi:10.1007/s10872-011-0031-6

Yin J (2012) Century to multi-century sea level rise projections from CMIP5 models. Geophys Res Lett 39:L17709. doi:10.1029/ 2012GL052947

Yin J, Griffies SM, Stouffer RJ (2010) Spatial variability of sea level rise in twenty-first century projections. J Clim 23:4585-4607

Zhang X, Church JA (2012) Sea level trends, interannual and decadal variability in the Pacific Ocean. Geophys Res Lett 39:L21701. doi:10.1029/2012GL053240 